Check for updates

New York, USA

Cite this as: $B M J 2020 ; 369: m 2459$ http://dx.doi.org/10.1136/bmj.m2459 Published: 18 June 2020

\title{
Ending US health inequalities needs multiple approaches, panel says
}

\section{Janice Hopkins Tanne}

Deaths from covid-19 among black Americans are almost double those of whites, and black, brown, and indigenous people face structural racism and health inequalities, an expert panel has said.

Not only are minority Americans dying at higher rates from covid-19, they are also dying at higher rates than whites from chronic diseases. Maternal mortality rates for black women are three or four times higher than for whites.

Although black Americans make up about $13 \%$ of the population, they account for $24 \%$ of deaths from covid-19, when race is known. About half of covid-19 deaths lack racial data, however, said Laurie Zephyrin, an obstetrician-gynaecologist who is vice president of the Commonwealth Fund. Similar disparities exist for Latino and indigenous Americans, she said.

Racial data on deaths is incomplete for most states and North Dakota does not report racial data, she said. When reported, deaths among Latino and indigenous people are higher than those for whites.

Among the reasons for the disparities are that these minorities are more likely to live in communities with pollution that predisposes them to health problems, less likely than whites to have health insurance, less likely than whites to be able to work from home, and face bias in medical treatment, she said. They are more likely to be unemployed because of the pandemic, and thus lose employment based health insurance.

The panel was organised by the Alliance for Health Policy, a nonpartisan, not-for-profit organisation focusing on better understanding of health policy, healthcare problems, and proposals for change; the Commonwealth Fund, which promotes a high performing healthcare system with improved access, quality, and efficiency, particularly for society's most vulnerable; and the National Institute of Health Care Management, a non-profit, nonpartisan organisation aiming to improve healthcare. ${ }^{1}$

Rachel Hardeman, a reproductive health equity researcher at the University of Minnesota, said that the pandemic showed what was not working. He said, "We have the opportunity to build a new system."

Wizdom Powell, director of the University of Connecticut Health Disparities Institute, said there was a link between people experiencing discrimination and poor physical and mental health. The disparities, both before the pandemic and now, "have significant implications for healthcare spending and worker productivity, and, thus, impact our capacity to compete in the global marketplace," she said.

Adaeze Enekwechi, a health policy expert at George Washington University, said that covid-19 infections are continuing to rise and 200 ooo people will likely have died by October. The US was unique globally in its dismal outcomes, she said. "We are the richest country in the world but we are seeing outcomes that look like what you might see in a poorer developing country." The current situation shows what needs to be done to combat the next pandemic, natural disaster, or public health crisis, she said.

Among the changes the panel recommended are better data, universal healthcare and an end to employment linked health insurance, and increased minority participation in the healthcare workforce.

Data on race, ethnicity, and English proficiency are needed to show where problems are.

Powell said, "We're not training enough black and minority health workers. We should open new paths into the community health workforce to people unemployed by the pandemic."

"We need more people of colour in the health workforce,” said Enekwechi. “They are more likely to go back to their communities after training-often in rural areas where trained workers are scarce and hospitals are closing."

They will help end antagonism to medical providers because they are trusted in the community and understand the community, she said. Minorities "have been experimented on, not given treatment, disrespected, and not treated for pain," she said. Lingering distrust will impair their responses to contact tracing and even to a vaccine when it becomes available.

Universal healthcare could be achieved if the US replaced employment based health insurance with an expansion of Medicare (government health insurance for the elderly) and Medicaid (health insurance paid for jointly by the federal government and some states). The Affordable Care Act encouraged states to expand Medicaid, but 14 states, mostly in the south, did not.

\footnotetext{
Alliance for Health Policy. Health inequities: addressing the disease burden in black, indigenous, and people of color communities. 16 June 2020 www.allhealthpolicy.org/covid-19-webinar-series-session-18-health-inequities-addressing-the-disease-burden-in-black-indigenous-and-peopleof-color-communities-4.

This article is made freely available for use in accordance with BMJ's website terms and conditions for the duration of the covid-19 pandemic or until otherwise determined by BMJ. You may use, download and print the article for any lawful, non-commercial purpose (including text and data mining) provided that all copyright notices and trade marks are retained.
} 